\title{
Correction
}

\section{Correction: De Francesco et al. In Vitro Characterization of Canine Microfragmented Adipose Tissue Non-Enzymatically Extracted from the Thigh and Lumbar Regions. Animals 2021, 11,3231}

\author{
Francesco De Francesco ${ }^{1, *,+} \mathbb{0}$, Valentina Riccio ${ }^{2,+}$, Reetuparna Biswas $^{3} \mathbb{D}$, Alice Busato $^{3}$, Caterina Di Bella ${ }^{2} \mathbb{D}_{\text {, }}$ \\ Evelina Serri ${ }^{2}$, Andrea Sbarbati ${ }^{3}$, Barbara Zavan ${ }^{4} \oplus$, Michele Riccio ${ }^{1}$ and Angela Palumbo Piccionello ${ }^{2}$
}

Citation: De Francesco, F.; Riccio, V.; Biswas, R.; Busato, A.; Di Bella, C.; Serri, E.; Sbarbati, A.; Zavan, B.; Riccio, M.; Palumbo Piccionello, A. Correction: De Francesco et al. In Vitro Characterization of Canine Microfragmented Adipose Tissue Non-Enzymatically Extracted from the Thigh and Lumbar Regions. Animals 2021, 11, 3231. Animals 2022, 12, 673. https://doi.org/10.3390/ ani12060673

Received: 29 December 2021 Accepted: 23 February 2022 Published: 8 March 2022

Publisher's Note: MDPI stays neutral with regard to jurisdictional claims in published maps and institutional affiliations.

Copyright: (c) 2022 by the authors. Licensee MDPI, Basel, Switzerland. This article is an open access article distributed under the terms and conditions of the Creative Commons Attribution (CC BY) license (https:// creativecommons.org/licenses/by/ $4.0 /)$.
1 Hand Surgery Unit, Department of Plastic and Reconstructive Surgery, Azienda 'Ospedali Riuniti di Ancona', 60126 Ancona, Italy; michele.riccio@ospedaliriuniti.marche.it

2 School of Biosciences and Veterinary Medicine, University of Camerino, 62032 Matelica, Italy; valy.riccio91@gmail.com (V.R.); caterina.dibella@unicam.it (C.D.B.); evelina.serri@unicam.it (E.S.); angela.palumbo@unicam.it (A.P.P.)

3 Department of Neuroscience, Biomedicine and Movement, Human Anatomy and Histology Section, University of Verona, 37179 Verona, Italy; reetuparna.biswas@univr.it (R.B.); alice.busato@univr.it (A.B.); andrea.sbarbati@univr.it (A.S.)

4 Department of Morphology, Surgery and Experimental Medicine, University of Ferrara, 44121 Ferrara, Italy; barbara.zavan@unife.it

* Correspondence: francesco.defrancesco@ospedaliriuniti.marche.it; Tel.: +39-071-5963945; Fax: +39-071-5965297

+ These authors contributed equally to the work.

\section{Addition of an Author}

Reetuparna Biswas was not included as an author in the original publication [1]. The corrected Author Contributions Statement appears here. The authors apologize for any inconvenience caused and state that the scientific conclusions are unaffected. The original publication has also been updated.

Author Contributions: Conceptualization, F.D.F. and V.R.; methodology, F.D.F.; validation, A.P.P., A.S. and M.R.; formal analysis, R.B., A.B., C.D.B., E.S. and B.Z.; investigation, F.D.F., R.B., A.B., V.R., resources, A.P.P. and M.R.; data curation, F.D.F.; writing—original draft preparation, F.D.F., R.B., A.B. and B.Z.; writing—review and editing, F.D.F. and A.P.P.; visualization, M.R.; supervision, A.S. and M.R.; project administration, A.P.P. All authors have read and agreed to the published version of the manuscript.

\section{Reference}

1. De Francesco, F.; Riccio, V.; Biswas, R.; Busato, A.; Di Bella, C.; Serri, E.; Sbarbati, A.; Zavan, B.; Riccio, M.; Palumbo Piccionello, A. In Vitro Characterization of Canine Microfragmented Adipose Tissue Non-Enzymatically Extracted from the Thigh and Lumbar Regions. Animals 2021, 11, 3231. [CrossRef] 